\title{
Contrasting Warlpiri and English Language Features
}

\author{
Dennis Michael Bryant (Corresponding author) \\ Faculty of Arts, University of Canberra \\ Kirinari Street, Bruce, Canberra, Australian Capital Territory, Australia \\ Tel: 61-04-0049-9265Ｅ-mail: DrDennisBryant@gmail.com
}

Received: August 18, $2021 \quad$ Accepted: September 9, $2021 \quad$ Published: September 10, 2021

doi:10.5296/ijch.v8i2.18950

URL: https://doi.org /10.5296/ijch.v8i2.18950

\begin{abstract}
If you were to think that the English language and the Australian Aboriginal Warlpiri language are poles apart in character and nature, you could be correct, at least in principle. There are differences, of course, but the intriguing question must be whether those language differences are sufficient enough to form a strong contrast between the languages. This paper proposes the thesis that a demonstration of just a small number of differences, each of which is critical in nature, would ensure that Warlpiri will be seen, not just as apart from English, but as worlds apart from English; that is, the Warlpiri language has cleaved loyally to its heritage of complexity, while English has cleaved far away from its now distant origins and could be described as simplistic when viewed against the complex richness of Warlpiri. The methodology used in this essay is to provide Warlpiri language exemplars across a small number of the diverse differences which make Warlpiri unique in its own ways, while listing a small number of differences that make English unique. This discussion should make understandable Warlpiri youth's recent drive to creating a parallel and successful version of their language.
\end{abstract}

Keywords: Australian Aboriginal Warlpiri language, New Youth-driven Warlpiri

\section{Introduction}

A number of Aboriginal languages have long been spoken in Australia. One of those Aboriginal languages is Warlpiri, spoken in parts of the Northern Territory and through to Western Australia, in places such as Yuendumu which is north-west of Alice Springs, or The Alice. When compared to English, spoken-Warlpiri is readily identifiable as an Aboriginal language due to a number of features that are foreign to English. While the following sections address a number of similarities, they also provide some discussion of the critical differences 
that exist between Anglo-Saxon English and the Warlpiri language which is described by Harrington as a member of the Pama-Nguyen family.

\section{The 'ng' Stumbling Block}

English often uses two letters, which together are referred to as a digraph, to represent a single sound. Examples would include 'ch', which occurs initially and finally in 'church'; and 'ng' which occurs in 'danger' in a medial position, but can also occur in a final position as in 'sang'. However, as English speakers are aware, 'ng' does not occur in an initial position; that is, English speakers have mastered 'ng' in two positions, but have never been required to master it in three positions. Therefore, were they to so encounter Warlpiri with a conviction to succeed, an initial 'ng' would amount to English speakers undertaking a sharp learning curve because an initial 'ng' sound is frequently found in many Australian languages - and Warlpiri is no exception to this pattern of placement. For example, 'ngapa' translates as 'water' whereas 'ngaka' would translate as 'later'. Moving to an example of a commonly-used salutation, which incidentally includes two occurrences of 'ng', 'ngaka nangku nyanyi' means 'see you later' but could be parsed up literally as 'later you see'.

\section{The Retroflex Stumbling Block}

There are, of course, further digraphs in Warlpiri that act as a potential challenge to new speakers. Two examples have been chosen as exemplars. One is the 'rn' digraph which appears in the verbal 'ngarn-i' and means 'eat' whereas 'ngarn-u' means 'eaten'. Just as 'ng' is a single sound written as a digraph, so too does ' $\mathrm{rn}$ ' indicate a single sound although it is written also as a digraph. The ' $r n$ ' digraph is essentially a retroflex ' $n$ ' sound; that is, in producing the ' $n$ ', one's tongue must flex backwards (hence, retroflex) in the production of the sound. By way of explanation, the use of a dash is not practised in Warlpiri orthography, but nevertheless is employed here to distinguish that portion of the word which carries the semantic underpinning, such as 'ngarn', from its grammatical inflection suffix ' $u$ ' or 'i'. Again, and highlighting another difference between English and Warlpiri, the ' $\mathrm{rl}$ ' is a further instance of a retroflex digraph, and this is exemplified in the first word of each exemplar below.

$$
\begin{array}{llll}
\text { Ju-rl-pungku } & & \text { ngarnu } & \text { ngapa' --- meaning '[the] bird drank [the] water'. } \\
\text { Ju-rl-pungku } & \text { ka } & \text { ngarni } & \text { ngapa' --- meaning '[the] bird is drinking water'. }
\end{array}
$$

Retroflex sounds are not found in most forms of English, and while they are not entirely anathema to English speakers, they are difficult to produce. Notably, there is a non-standard form of American English in which a retroflex 'l', written as a digraph 'rl', does occur, and one instance of this can be heard in that dialect's production of 'girl'. But for English in general, this is not a commonly found occurrence. One additional comment needs to be made concerning the exemplar: that is, the English definite article 'the', which serves as a free morpheme in a discourse to precede a known or assumed to be commonly known noun, is absent in Warlpiri. Having explored difference, the above two examples do point to one similarity that exists between Warlpiri and English in that they both feature vowel alternation, at a verbal level. Examples in English would be 'run, ran; take, took' and these are known as 'strong verbs' where strong is taken to mean verbs which have persevered unchanged from Old English times, and therefore do not conform to today's dominant verb pattern of 
constructions. Therefore, a vowel alternation similarity is present, yet tenuous in extent. In that sense, English is a strayer from its origins and probably a frequent one at that, while Warlpiri might be interpreted to be loyal to its past, or stated in equivalent terms, a stayer.

\section{The Joy of Euphony}

If there is a feature that is found in abundance, but which clearly differentiates Warlpiri from English, then it must be euphony. In fact, Warlpiri seems to feverishly rejoice, and exhibit a strong regard for, euphony in everyday language. Some examples follow that will demonstrate Warlpiri's joy.

Yantarra ngurra-kurra!

This exemplar translates as 'Go-in a direction that is most effectively away from me'; specifically, 'to your own lodgings'. Effectively, this constitutes a polite, but firm, request to buzz off home. Whereas English employs free-form prepositions whose placements are pre-nominal (Greenberg, 1973), as in 'to our camp', the Warlpiri people prefer post-nominal positioning of prepositions, as shown in 'ngurra-kurra'. Conveniently, this Warlpiri construction can be written by using a hyphen to associate a nominal and a preposition that are intended to form a semantic cluster.

Yantarra yuwarli-kirra!

Notable for its euphonic-change, 'kurra' has an alternate form, which is 'kirra', and its usage is evident in the exemplar above. As a further example, and using 'pirli' as the semantic underpinning for 'rock', in order to express 'to the rock' would also require a remapping of 'kurra' as in 'pirli-kirra' in which a high-vowel 'i' occurs in the final segment of 'pirli', and this similarly impacts preposition realisation to also feature a high-vowel, as shown, in a medial position.

\section{The Case Stumbling Block}

To understand the nature of Warlpiri, it is necessary to reflect on case because it is one of the grammatical dictates that could be expected to cause difficulties to newcomers. Case is a feature that Warlpiri has in abundance which starkly differentiates it from English, but it is also true that the presence of case includes Warlpiri in a fraternity that contains Russian and Arabic (Bryant, 2021). Case is a feature that requires a complexity of construction which entails strict adherence to building grammatical inflections on nouns, which is called 'case marking'. While such case markings might be seen as concise, and perhaps even admired as elegant word construction, there is a reputed downside. It has been argued elsewhere that an over-fondness for expanding basic words by building upon them inflections that are essentially semaphores to signal grammatical metadata is costly to learning and communication (Bryant, 2021). The negative implication is that loading grammatical indicators onto semantic stems can be thought of as antithetical to discourse in so much as it is a departure from simplicity.

If there is a difficulty in English speakers learning Warlpiri as a second language, case must surely be a blockade for those learners who have not experienced case languages. However, it 
must be admitted that this prior remark would not hold for speakers whose native language was a case language, as they would be at ease with nominal extension in a way that English speakers are no longer experienced. Consider, for example, 'jurlpu' which was used in a previous exemplar as the semantic underpinning for 'bird'. When demonstrated in a simple SVO declarative (Greenberg, 1973), its form is:

'Jurlpu-ngku ngarnu ngapa' meaning '[the] bird drank [the] water'.

It is noticeable that the underpinning word in the subject position has been inflected to also carry a suffixed '-ngku' case marking which is intended to indicate it stands as a subject. However, there is an absence of marking on the object, 'ngapa'. There could be two explanations for such absence. Either, an inflection is not needed because the communication is clear enough, and this is often the reality; else the way is kept clear for an alternative marking to be used, as shown in the exemplar below.

'Jurlpungku ngarnu ngaparla' meaning 'Bird drank at-waterhole-here.'

In the exemplar above, an '-rla' inflection has been added to mean location. Although this is a simple communication, it does suggest an underlying complexity. Dixon hints at this underlying complexity by providing implicitly numerous nominal inflection forms, but also explicitly by seeming to note that his own 'Rule 2' analysis is not robust [p. 560]. Additionally, he points to 'irregular ergative' as well as 'irregular locative' [p. 560]. For our purposes, 'ergative' can be thought of as a marking on a subject noun. But the point is clear: complexity abounds and it sometimes defies description, even by a senior trained linguist.

Continuing the Warlpiri theme, 'yuwarli' includes an 'rli' retroflex sound as the final part of its root word and translates as 'house', but it does not translate as 'at home'. To become 'at home' would require a locative ending, which happens to be '-rla'. When combined, 'at home' would be 'yuwarli-rla'. That is, there are two adjacent retroflex sounds, 'rli' followed by 'rla'. While English speakers might hesitate at a single retroflex, they surely might even stumble at adjacent retroflexes. This is not to say that Warlpiri speakers would find any difficulty with 'yuwarli-rla'.

So far, little or no mention has been made of endings being added to a person's name. Robin Japanangka Granites, an author who wrote 'Kuwana-Kurlu' (which translates as 'Goanna-About') signs himself off interestingly as Robin JapanangkaRLU YurntumuRLA. The endings of interest here have been capitalised. The RLU suffix would be intended to infer that Robin was a integral cause of the publication; while the RLA suffix would indicate that publication was achieved at Yurntumu (Yuendumu) in the Northern Territory. Efficiently neat!

Unlike Warlpiri, today's English does not build case structures on its nouns. However, there is an irony here, because a predecessor form of English, namely the Old English language, was built on case. Surprisingly, a hint of the former Old English case systems does survive today — in the various forms of today's pronouns; for example, in 'they, them, their'. Possibly high usage rates has ensured their longevity. However, with regard to nouns, the need for case was eliminated when English moved to a 'positional inference' system (Bryant, 2021); that is, 
usage of a word may occur in any of the three SVO positions and that position defines a word's significance to a communication. In other words, there has been an elimination of the need to build-in a costly grammatical interpretation onto a word, thereby achieving almost zero grammatical interpretation cost in English communications. Although this claim may sound exaggerated, this exceptionally low cost of communications may have contributed to English becoming a world language. Even though Warlpiri is a language with many fascinations, it would take a replete abundance of optimism to believe that its structural costs would not hinder its rise to such heights.

Reversing the comparison, today's English has almost zero complexity (Bryant, 2021) to be admired when compared to Warlpiri's feast of features, some of which have been discussed so far. Therefore, it was no exaggeration to juxtapose 'complexity' and 'Warlpiri' in the same sentence. This will become obvious when the discussion turns to combining Warlpiri case formations with Warlpiri's euphony, which was touched on very briefly in an earlier section. One way to approach combining case formations with euphony is to think in terms of syllables, because word length when measured in syllables is a force in Warlpiri thinking, and the ensuing section will now explore this point briefly.

\section{The '-ngku' Versus '-rlu' Stumbling Block}

Given Warlpiri's fascination with syllables and euphony as seen in the 'kurra, kirra' alternatives, it may come as little surprise that Warlpiri is also concerned with syllable length. At the very least, any adaption to grammatical ending could be thought of as just another step towards a continued desire to achieving grammatical euphony and complexity. It almost appears to constitute a desire to test the limits of communication options, albeit in a controlled and intelligent, and perhaps even an amusing manner. If it appears to be a game that was designed in days now past, it must be admitted that it was an intellectual game that succeeded into the present.

The stock of words in Warlpiri can be divided into those words which comprise of two syllables, and those words which are greater in length. The inference is that word length determines which one, of the two possible, nominative-inflections must be chosen; ironically by number, a two syllable -ngku inflection is at home with a two-syllable word; and the remaining single-syllable grammatical marker, -rlu would be pressed into service elsewhere. There is, of course, one further complication, and this is the need to cater for euphony. Accordingly, the earlier statement must be modified to now contain euphony pairs, rather than single member sets. This gives a pair of two-membered sets. These pairs are, -ngku allied to -ngki; and -rlu allied to -rli. Exemplification follows.

Yapa-ngku ka Naparrula pakarni. 'A man is hitting Naparrula'.

Ngati-ngki ka pakarni Nungarrayi. 'The woman is hitting Nungarrayi'.

Nantuwu-rlu ka muku nyanyi. 'The horse is looking around'

Jungarrayi-rli ka Jakamarra pakarni. 'Jungarrayi is hitting Jakamarra'. 


\section{The Joy of Youthful Entrepreneurship}

Today, perhaps there is a common tendency to associate the word entrepreneurship with matters financial. However, in the context of today's Warlpiri youth, the word entrepreneurship is intended to cast a very positive light and even a hint of brilliance onto Warlpiri-speaking youth who have managed to create what may be called a new edition of Warlpiri. This new edition is called Warlpiri-Lite. The emergence of the Lite edition has been reported by O'Shannessy (2005), who notes that Warlpiri-speaking youth deploy standard Warlpiri in communicating to their tribal elders and at times of public formality; are able to comprehend standard Warlpiri that is delivered to them by their tribal elders; yet speak Lite amongst themselves. It seems that this youthful edition is a genuinely realistic ploy to bring the past up-to-date in order to make their future more secure.

While a case system similar to Warlpiri existed in Old English, the demise of Old English case occurred over centuries but, amazingly, youthful Warlpiri modifications seem to have happened in the blink of an eye, and with resolved determination, and was possibly seen as normal change, with no disrespect intended by the new generation who carry a language forward.

\section{An Unexpected Constraint / Absence}

On the topic of pronunciation, which is also referred to as the phonology of a language, Butcher (2018) notes that Australian languages have 'an unusually large number of places of articulation', presumably meaning that having retroflex points is not unusual. However, it is unclear as to whether Butcher is presenting a factual or a Romantic view on this point. To arrive at that opinion, Butcher would have taken into account the fact that fricatives and affricates are not evident in the Warlpiri phonology set. It is generally accepted that nine fricatives are possible and available to languages, the most obvious of these being ' $f, v$ ' pairing in which the first member is considered to be lightly voiced in speech, whereas the second member is more fully voiced. With regard to phoneme placement in the mouth, both 'f, v' are considered to happen as labio-dentals, where 'labio' indicates 'lips' and 'dental' indicates 'near the teeth'. A deeper insight into general phonology and phonetics can be found in Abercrombie (1967), and in O'Connor (1973). However, a close investigation into Butcher's choice of 'unusually large number of places of articulation' may be interpreted to be excessive in interpretation, because an absence of fricatives with regard to Warlpiri implies fewer places of articulation, which is not necessarily congruent with a statement claiming 'an unusually large number of places of articulation'. But one criticism of Butcher (2018) doth a winter not make. Butcher's medical argument surrounding 'otitis media' and the non-suitability of fricatives for Aboriginal speakers in desert conditions is very well-made.

In continuing the theme of difference between English and Warlpiri, when first involved with Warlpiri, English speakers would probably find the absence of the ' $S$ ' phoneme as the most surprising. As English speakers would appreciate, English could not survive without this letter, which is used grammatically to indicate plurality; and together with an apostrophe, is used to indicate a relationship often of ownership; as in 'Anne's car'; as well as being used in the 
construction of words which perform a semantic role rather than a grammatical role. Of course, the 'of' participle could be used in lieu of an apostrophe-S construction, but its overuse might prove cumbersome and this point is argued elsewhere (Bryant, 2020b).

Additionally, although Warlpiri may have many fascinations, it is well to remember that Warlpiri does not share with English a fascination concerning articles such as definite 'the' and indefinite 'a' (Bryant, 2020a); nor a simplicity of construction (Bryant, 2020c).

There are substantially more differences that distinguish English from Warlpiri - in fact too many to deal with successfully in a single essay. However, in one such difference, English has sought and achieved major simplicity such as 'positional inference' (Bryant, 2021) within an Subject-Verb-Object sentence in order to eliminate any need for English to deploy case endings that would function as semaphores of intended function, to the degree that it has been taken up as a world language.

But perhaps there is one further difference that operates almost silently, yet is critically-used in English but is not critical to Warlpiri; namely, that voicing is not significant in Warlpiri. In other words, Warlpiri speakers would at first interpret 'pin' and 'bin' as representations of the same word, and would have to school themselves in recognising them as independent words.

To illustrate this point, with a sense of humour added in, were you to be called a 'pani pucker' by a Warlpiri speaker, should you be alarmed, amused or nonplussed, and just as importantly, is there clarity of meaning in this brief phrase? Before answering, the reader should be aware that both words have their genesis as English words. However, when used within the Warlpiri phoneme rules, small changes can seem insurmountable to the expectations of an English listener. But there is a 'funny bugger' in every language, is there not? As a closing comment, and again indicating the novelty of Warlpiri, a clear majority of world languages are believed to distinguish between voiced and unvoiced sounds; not so Warlpiri.

\section{Conclusion}

This essay laid out a small but arresting number of features that occur in the Warlpiri language of the Northern Territory of Australia. One of the features was a feverish joy towards euphony. This feverish joy should impress speakers of English which has little or no feeling for euphony, but it must be admitted that English does excel in simplicity of operation, and has become the world norm for international communication. However, and this is a negative to Warlpiri, when Warlpiri is evaluated in terms of ease of use, Warlpiri is hampered severely by its almost religious adherence to Case. But the day of the youthful entrepreneur has arrived, and the Warlpiri youth have positively taken over the reins and that move could make Warlpiri, and its joyful euphony, much more accessible to wider spread audiences sometime soon.

\section{Postscript}

Warlpiri booklets do not always acknowledge authorship, and this may be due to cultural factors beyond the scope of this paper. However, all the booklets that were consulted in writing this paper have been acknowledged. The writer has taken the view that it is more 
important, on this occasion, to display the joy of Warlpiri writers even if a European-centric norm was not fully met.

\section{References}

Abercrombie, D. (1967). Elements of General Phonetics. Edinburgh: Edinburgh University Press.

Bryant, D. M. (2020a). The Form and the Function that Defines and Associates Definite and Indefinite Articles in English Grammar. International Journal of Culture and History, 7(1), 30-40. Retrieved from http://www.macrothink.org/journal/index.php/ijch/article/view/17213 https://doi.org/10.5296/ijch.v7i1.17213

Bryant, D. M. (2020b). Pursuing the Energetic yet Enigmatic Particle that Powers English Communication. International Journal of Culture and History, 7(2), 38-46. Retrieved from http://www.macrothink.org/journal/index.php/ijch/article/view/17488

https://doi.org/10.5296/ijch.v7i2.17488

Bryant, D. M. (2020c). Focussing on Revealing English Grammar's Conceptual Unity amidst its Operational Diversity. Language, Literature and Culture, 3(2), 8-14. Retrieved from http://www.aascit.org/journal/archive2?journalId=932\&paperId=7825

Bryant, D. M. (2021). Why neither Russian nor Arabic will become world languages. International Journal of Culture and History, 8(1), 143-152. https://doi.org/10.5296/ijch.v8i1.18650

Butcher, An. (2018). The special nature of Australian phonologies: Why auditory constraints on the sound systems of human languages are not universal. The Journal of the Acoustical Society of America, 144(3), 1939. https://doi.org/10.1121/1.5068481

Dixon, R. (1977). A grammar of Yidin. Cambridge University Press. Cambridge. https://doi.org/10.1017/CBO9781139085045

Granites, R. J. (1976). Kuwana-Kurlu. Yuendumu school press.

Greenberg, J. H. (1973). Some Universals of Grammar with Particular Reference to the Order of Meaningful Elements. In J. H. Greenberg (Ed.), Universals of Language (pp. 73-113). London: MIT Press.

Harrington, J. (n.d.). The phonetics and phonology of Australian Aboriginal languages. Macquarie University. Retrieved from https://www.mq.edu.au/about/about-the-university/faculties-and-departments/medicine-and-h ealth-sciences/departments-and-centres/department-of-linguistics/our-research/phonetics-andphonology/speech/phonetics-and-phonology/australian-aboriginal-languages

Langdon, P. J. (1975). Wana. Yuendumu.

Langdon, P. J. (n.d.). Kinkikirli. School of Australian Linguistics, Darwin Community College. 
Martin, G. N. (1977). Nantuwu-Kurlu manu Wirriya-Kurlu. Science Research Associates. Chicago.

No author. (1975). Ngarni ka Ngarnu: Warlpiri. Yuendumu school press.

No author. (1975). Wati ka ngunami yujukurla. Yuendumu school press.

No author. (1976). Warlpiri wangkanja puku. Yuendumu school press.

No author. (1976). Wirlinyi. Yuendumu school press.

No author. (1977). Warlpiri: wangkanja-Kurlangu puku 6. Yuendumu school press.

O’Shannessy, C. (2005). Lite Warlpiri: A New Language. Australian Journal of Linguistics, 25(1), 31-57. https://doi.org/10.1080/07268600500110472

O'Connor, J. D. (1973). Phonetics. Language \& Linguistics. Harmondsworth, England: Penguin Books.

Robertson, G. J. (1974). Malikipardu-kurlu Yimi. School of Australian Linguistics, Darwin Community College.

Robertson, G. J. (1975). Marlungku karla warrirni ngurraku. Yuendumu school press.

Spencer, L. J. (1976). Nyiya kuja karlipa ngarni. School of Australian Linguistics, Batchelor.

\section{Copyrights}

Copyright for this article is retained by the author(s), with first publication rights granted to the journal.

This is an open-access article distributed under the terms and conditions of the Creative Commons Attribution license (http://creativecommons.org/licenses/by/4.0/) 